\title{
ALLOWABLE POWER IN NiCr FILM RESISTORS
}

\author{
T. BERLICKI and E. PROCIÓW \\ Institute of Electron Technology of Technical University, 50-370 Wroclaw, Poland
}

(Received April 15, 1981; in final form October 20, 1981)

\begin{abstract}
This paper reports the dependence between the power required to cause destruction and the dimensions of resistive films, i.e. the width and thickness. The dependence has been analysed using destruction phenomenon models which consider the increase of temperature of the resistive films and the films defects. Results show that the power value required to cause destruction rises linearly with the width of the resistor films and is exponentially proportional to the sheet resistance.
\end{abstract}

\section{INTRODUCTION}

The maximum value of power density of a resistive film is an essential factor in the designing of thin film resistors. ${ }^{1}$ This parameter is dependent on the allowable maximum temperature of the film and on the size and density of the defects. Also the maximum power of the resistor is dependent on the geometry of the resistor, i.e. the length, width and thickness, as well as on the kind and dimensions of the substrate. ${ }^{2}$ The influence of the width and of the sheet resistance of the resistive film are discussed in this paper.

\section{EXPERIMENTAL}

The resistors were deposited on to Corning 7059 glass substrates, which had dimensions $30 \times 20 \times 0.8 \mathrm{~mm}$. For the temperature measurement nickel film resistors were used, which have a relatively high temperature coefficient of resistance, TCR $=+3 \times 10^{-3} / \mathrm{K}$. From such resistors it is possible to obtain temperature measurements with high precision. The resistor dimensions were: width $1 \mathrm{~mm} \pm 0.1 \mathrm{~mm}$ and length $15 \mathrm{~mm}$. For the measurements of the power to destroy the film, $\mathrm{NiCr}$ film resistors were used TCR $=(-60 \div-120)$ $\times 10^{-6} / \mathrm{K}$ which have a width of $1 \mathrm{~mm} \pm 0.1 \mathrm{~mm}$ and length $7 \mathrm{~mm}$.

The correlation between the width of a film carrying a current and temperature has been measured.

The average temperature of the resistive film can be calculated from the current and voltage values, which need to be measured exactly. The relation between the thermal conductance, $P / \Delta T$ ( $\Delta T \equiv$ difference of temperature; $P \equiv$ power) and the width of the resistive film is shown in Figure 1.

This dependence is a straight line which can be written as:

$$
\frac{P}{\Delta T}=a_{1}+b_{1} w
$$

where $a_{1}, b_{1}$ are constants and $w$ is the width of the resistive film.

The correlation between power to destroy the film and width of the resistive film was also measured. The applied voltage was increased linearly at $5 \mathrm{~V} / \mathrm{min}$, which

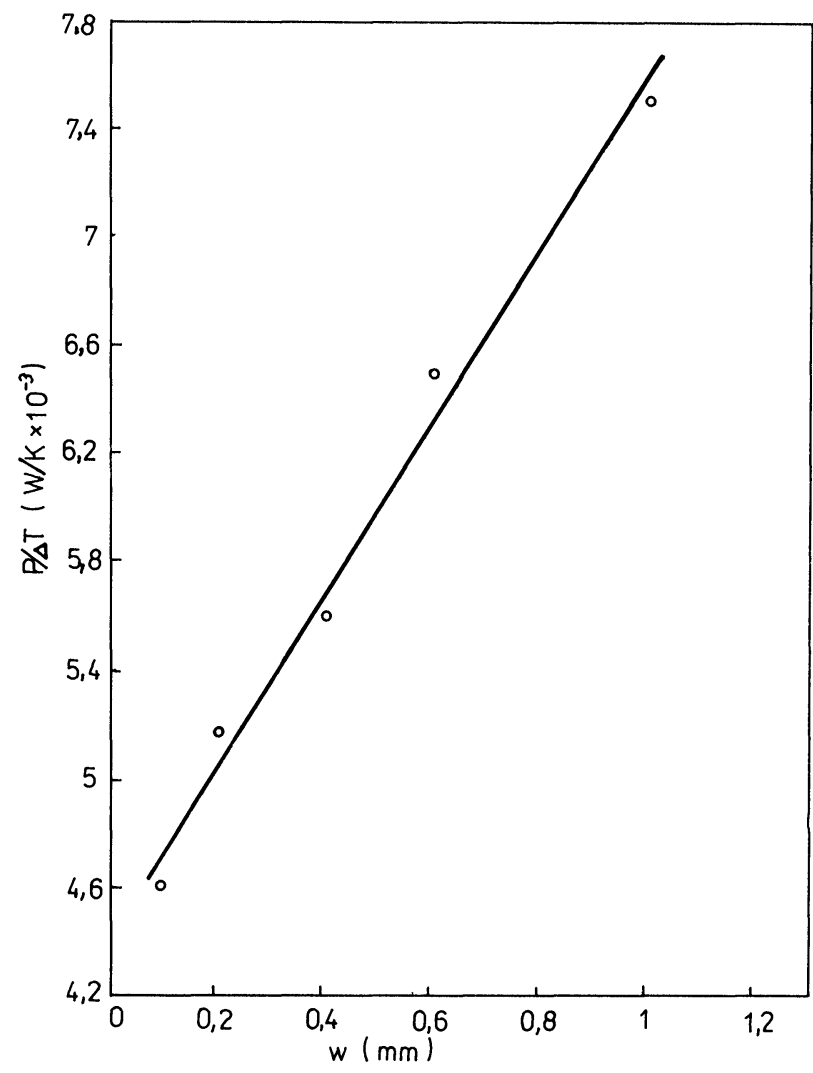

FIGURE 1 Thermal conductance as a function of the width of a resistive film. 
gave a parabolic increase of the power (in the range where the resistance remains constant). Experimental values are plotted in Figure 2, and the destroyed resistor is presented in Figure 3.

The curve obtained can be described by a straight line equation

$$
P_{\mathrm{d}}=a_{2}+b_{2} w
$$

where $a_{2}$ and $b_{2}$ are constants and $P_{d}$ is the power to cause the film to be destroyed.

The relation between the $\mathrm{NiCr}$ sheet resistance $R_{\square}$ and the power to destroy the film was also measured. The data has been plotted against sheet resistance on a log-log scale in Figure 4.

\section{RESULTS AND DISCUSSION}

H.T. Law ${ }^{3}$ has given an analysis of the dependence of the temperature of resistor on the width. This relation is a result of the fact that the heat is dissipated from the area of the resistive film and from the part of the substrate surrounding the resistor. The heat dissipated from the resistive film is dependent on its area which means that it is a function of the width of the resistive film. The heat losses from the substrate and from the area in the vicinity of the resistor are

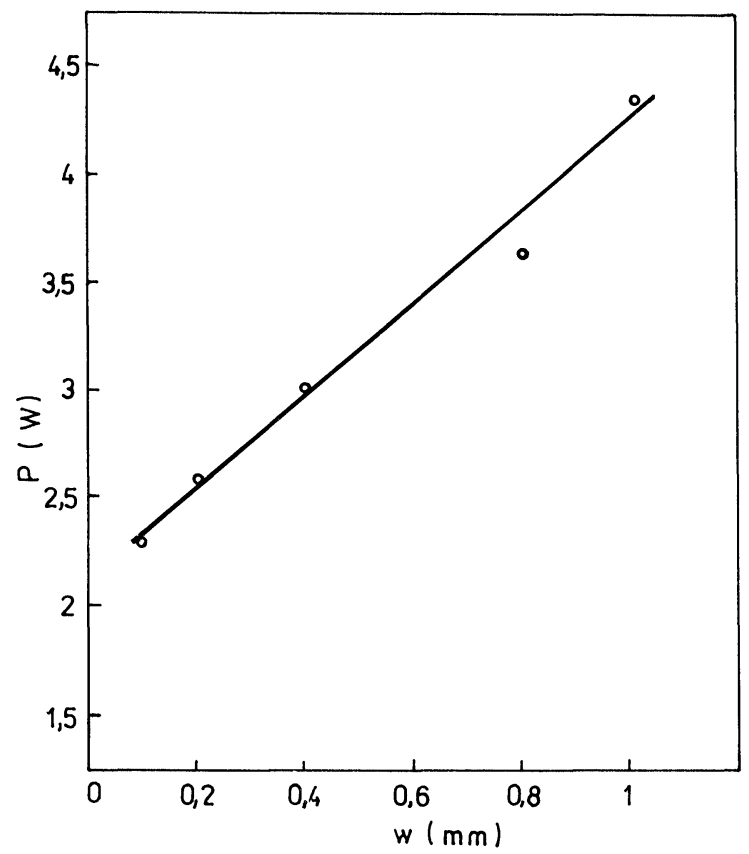

FIGURE 2 Power for open circuit as a function of the width of the resistive film.

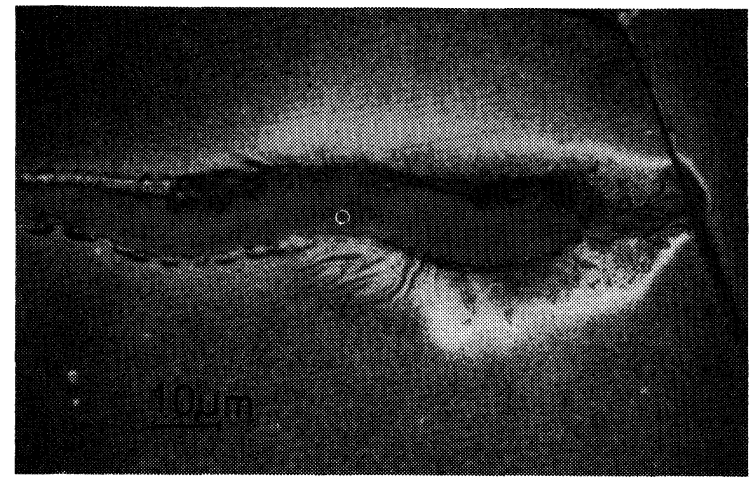

FIGURE 3 Micrograph of destroyed $\mathrm{NiCr}$ resistive film.

independent of the width of the resistive film. This assumption is approximately correct for certain width ranges. Experimental values have been shown in Figure 1.

Resistors are destroyed at weak spots. The value of the power to destroy the film is limited by the temperature and is dependent on the film defects. These defects cause a reduction of the cross - section area of the resistor film and the power for destruction is dependent on the ratio of the cross - section of the resistor film at the weak spot to the cross section on the film without any defects.

This ratio is dependent on the film width. The destruction of a resistor takes place at a weak spot by a change of cross - section. This process can be caused by electromigration or by oxidation. Electromigration as the destruction mechanism has been described ${ }^{4,5}$ but at higher temperatures oxidation can also occur. When films have protective layers the power required to destroy the films is higher because of the reduced access of oxygen. In the final period of the destruction process a large change of the resis-

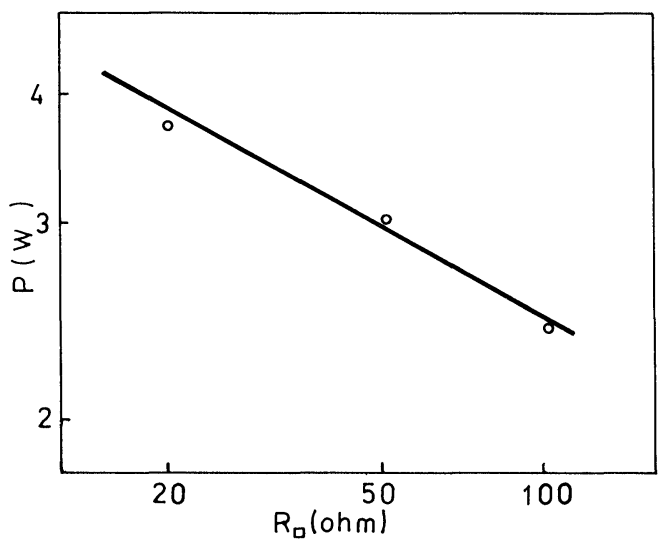

FIGURE 4 Power for open circuit as a function of sheet resistance. 
tance is observed, melting of the film then follows and the film stops carrying current.

If it is assumed that at the critical time only one of the destruction processes is important, then one can write that $\mathrm{t}^{5-7}$

$$
D=\left(\frac{\Delta \sigma}{\sigma_{0}}\right)^{\beta_{1}}=A R_{\square}^{\beta} t \exp \left(-\frac{B}{T_{w s}}\right)
$$

where the parameter $D$ is an exponential function of the relative change of cross - section area of the resistor film $\Delta \sigma / \sigma_{0}, \sigma_{0}$ is the initial cross - section of the film, $R_{\square}$ is the sheet resistance, $A, B, \beta_{1}$ and $\beta$ are constants and $T_{w s}$ is the temperature at the weak spot.

The relation of the temperature at the weak spot to the applied power can be written approximately as:-

$$
T_{w s}=T_{a}+k_{1}(P-\Delta P)+k_{2} \Delta P
$$

where $T_{a}$ is the ambient temperature, $P$ is the power dissipated in the resistor, $\Delta P$ is the power dissipated in the weak spot and $k_{1}, k_{2}$ are constants.

The destruction process can be divided into two periods: the first one in which a slow change of the resistance (cross - section areas) of the film at the weak spot takes place and a second period in which a quick change of the resistance at the weak spot and a quick increase of the temperature at this spot occurs.

The second period is much shorter than the first period, and can be written, if $P \gg \Delta P$ :-

$$
\begin{aligned}
1 & =A R_{\square}^{\beta}\left[\exp \left(-\frac{B}{T_{a}+k_{1} P+k_{2} \Delta P}\right) t_{1}\right. \\
& \left.+\exp \left(-\frac{B}{T_{a}+k_{1} P+k_{2} \Delta \tilde{P}}\right)\left(\tau-t_{1}\right)\right]
\end{aligned}
$$

where $t_{1}$ is the time of the first period, $\tau$ is the total life time. If in the first period $k_{2} \Delta P \ll k_{1} P$ and if $\left(\tau-t_{1}\right) \ll t_{1}$, then

$$
1=A R_{\square}^{\beta} \exp \left(-\frac{B}{T_{a}+k_{1} P}\right) \tau
$$

and hence

$$
\tau=\frac{1}{A} R_{\square}^{-\beta} \exp \left(\frac{B}{T_{a}+k_{1} P}\right)
$$

where $T_{a}+k_{1} P=T$ is the average temperature of the resistor. If the applied voltage is increased linearly, i.e.

$$
U=c \cdot t
$$

hence

$$
P=\frac{(c \cdot t)^{2}}{R_{\square} \frac{l}{w}}
$$

and

$$
D=\int_{0}^{t} A R \xi \exp \left\{-\frac{B}{T_{\mathrm{a}}+\left(k_{1} c^{2} w t^{2}\right) /\left(l R_{\square}\right)}\right\} \mathrm{d} t
$$

where $l$ is length of the resistor film, $c$ is a constant. From Eq. (8) by approximation for $D=1$ we have

$$
1=A_{1} R_{\square}^{\beta-\alpha / 2} \tau_{d}=A_{2} R_{\square}^{\beta} P_{d}^{\alpha / 2}
$$

Hence

$$
P_{d}=\frac{1}{A_{2}} R^{-2 \beta / \alpha}
$$

where $\tau_{d}$ is the life time of the resistors for a linear increase of the applied voltage, $A_{1} A_{2}, \alpha$ are constants. The parameter $2 \beta / \alpha$, as calculated from Figure 4 , is 0.28 .

\section{REFERENCES}

1 R.W. Berry, P.M. Hall and M.T. Harris, Thin film technology, (D. Van Nostrand Company, Inc., 1968)

2 G.P. Ferraris and M. Tudanca, Proceedings European Hybrid Microelectronics Conference Ghent, Belgium, pp 61-73, (1979)

3 H.T. Law, Proceedings European Hybrid Microelectronics Conference Ghent, Belgium, pp 9-19, (1979)

4 R.S. Mo and D.M. Gilbert, J. Electrochemical Society 120, pp 1001-1003, (1973)

5 W.F. Keenan and W.R. Runyan, Microelectronics and Reliability, 12, pp 125-138, (1973)

6 A. Mihalyi, E. Jets and S. Bross, Proceedings of the Second Colloquium on Thin Films, Budapest, pp 555-560, (1967)

7 I. Blech, H. Sello and L.V. Gregor in Handbook of Thin Film Technology (Ed. L.I. Maissel, R. Glang) (McGrawHill N.Y.) pp 23-16 

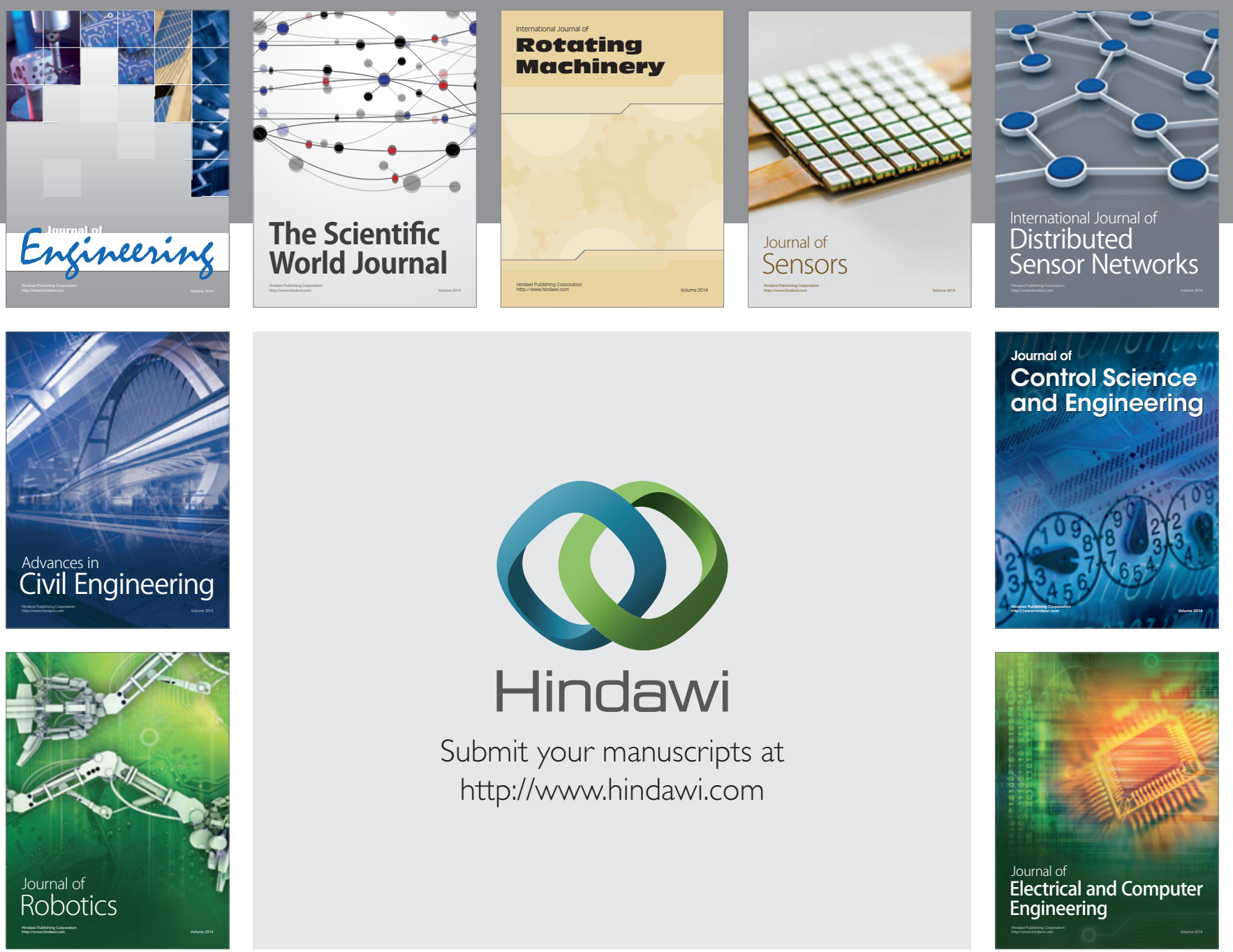

Submit your manuscripts at

http://www.hindawi.com
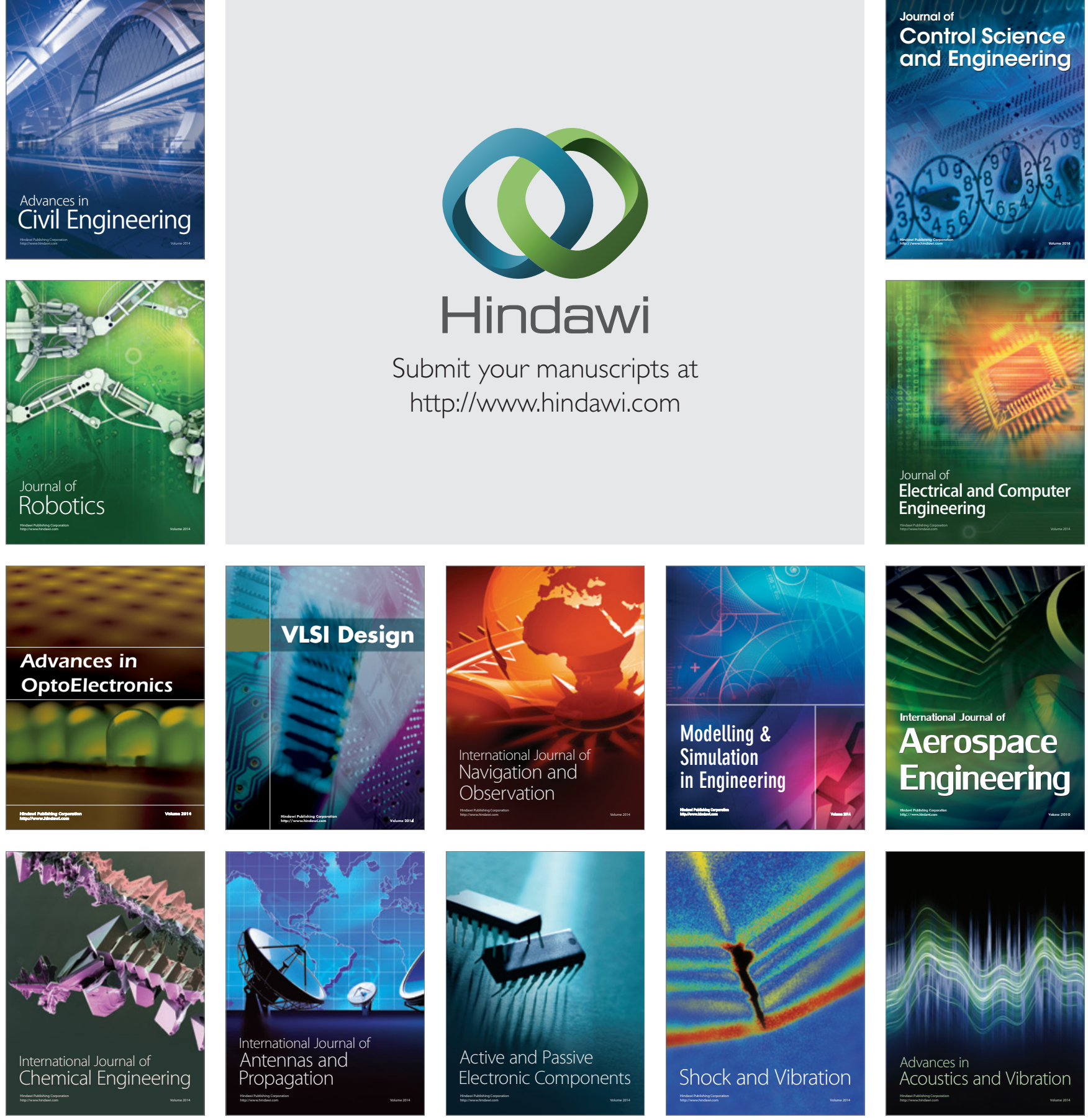